\title{
Políticas e práticas de formação de professores de Ensino Religioso: desafios, avanços e perspectivas
}

\section{Policies and practices of Religious Education professor's training: challenges, progress and prospects}

\section{Lurdes Caron}

Doutorado no Programa de Pós-Graduação em Educação, pela Pontifícia Universidade Católica de São Paulo (PUC-SP), São Paulo, SP - Brasil, e-mails: lurcaron@gmail.com e lurcaron@terra.com.br

\section{Resumo}

O Ano Brasileiro de Ensino Religioso (ER) desafia docentes e pesquisadores envolvidos com a formação de professores de ER a marcar a diferença. Nas décadas de 1980 e 1990, várias instituições (religiosas ou não) organizavam cursos, seminários e encontros para formação de professores de ER. A Licenciatura Plena em ER aconteceu a partir de 1996 e Santa Catarina foi o Estado pioneiro na formação de professores com essa habilitação. A pesquisa descreve experiências de instituições religiosas e outras com a formação de professores de ER e destaca a experiência de Santa Catarina, a partir de 1996, com o Curso de Ciências da Religião - Licenciatura Plena Habilitação em Ensino Religioso (CCR/LP/ER). A formação de 
professores de ER com Licenciatura Plena, em Estados da Federação Brasileira, ainda é carente de políticas públicas.

Palavras-chave: Ensino Religioso. Formação de professores. Políticas públicas.

\section{Abstract}

The Brazilian Year of Religious Education challenges teachers and researchers involved in Religious Education (RE) training to make the difference. In the decades of 1980 and 1990, several religious and non-religious institutions carried out courses, seminars and workshops to form RE professors. Santa Catarina state pioneered in full-degree Religious Education programs, that started to be held in 1996. The present study describes the experience of religious and non-religious institutions in the training of full-degree RE professors, emphasizing the case of Santa Catarina. The formation of full-degree RE professors in Brazil still lacks public policies.

Keywords: Religious Education. Teacher formation. Public policies.

Quem ensina aprende ao ensinar, e quem aprende ensina ao aprender. [...] O professor que pensa certo deixa transparecer aos educandos que uma das bonitezas de nossa maneira de estar no mundo e com o mundo, como seres históricos, é a capacidade de, intervindo no mundo, conhecer o mundo [...]. Pesquiso para constatar; constatando, intervenho; intervindo, educo e me educo. Pesquiso para conhecer o que ainda não conheço e comunicar ou anunciar a novidade (FREIRE, 2002, p. 25, 31-32).

\section{Introdução}

No ano Brasileiro do Ensino Religioso, lançado dia 15 de outubro de 2009, é de suma importância que todos os pesquisadores e docentes envolvidos com a formação de professores deEnsino Religioso (ER) possam dedicartempo para: (re)avaliar, (re)pensar, (re)visar, (re)planejar, (re)organizar e (re)escrever políticas e práticas para a formação de professores, nesses últimos 15 anos. 
O Ensino Religioso na História da Educação Brasileira, no imaginário de grande parte da população - de modo especial no de homens públicos (políticos) -, soa como disciplina curricular ambígua, de conflitos entre a liberdade religiosa, de ser disciplina curricular e, ao mesmo tempo, administrada e gerenciada ora pelos sistemas de ensino, ora por instituições religiosas. Em alguns momentos, é uma disciplina da área de conhecimento entre a dinâmica de (re)construção e de (in)exclusão do sistema escolar; em outros encara desafios quanto à interpretação da legislação de ensino e à exigência de formação de professores de ER, ora contando com iniciativas animadoras, ora se deparando com ausência de efetivas políticas públicas inclusivas de formação de professores para esta disciplina.

A Lei de Diretrizes e Bases da Educação Nacional (LDB), Lei n. 9.394/96, define, no Artigo 62, que a formação de docentes para atuar na educação básica será realizada em nível superior, em curso de Licenciatura, de Graduação Plena, em Instituições de Ensino Superior (IES). O parágrafo $1^{\circ}$ diz que a União, o Distrito Federal, os Estados e Municípios, em colaboração, deverão promover a formação inicial, a continuada e a capacitação dos profissionais para o magistério. O Artigo 67 descreve que os sistemas de ensino promoverão a valorização do profissional da educação.

O Artigo 33 da Lei n. 9.394/96, na redação alterada pela Lei n. $9.475 / 97$, define no parágrafo $1^{\circ}$ que os sistemas de ensino regulamentarão os procedimentos para a definição dos conteúdos do ensino religioso e estabelecerão as normas para a habilitação e admissão de professores.

Após 13 anos de experiência da lei n. 9.475/97, é tempo de rever, celebrar e planejar a formação de professores de ER, com efetivas políticas públicas, de acordo com o Plano Nacional de Formação de Professores da Educação Básica desenvolvido pelo MEC.

Este artigo compreende três partes:

1) a experiência de instituições de ensino e entidades religiosas na promoção de eventos para a formação de professores de ER nas décadas de 1980 e 1990;

2) a experiência do Fórum Nacional de Ensino Religioso (Fonaper), a partir de 1995;

3) a experiência do Estado de Santa Catarina, a partir de 1996, com o Curso de Ciências da Religião - Licenciatura Plena - Habilitação de Professores em Ensino Religioso. 


\section{Formação de professores: iniciativas de entidades religiosas e educacionais}

Enquanto não existia curso de Licenciatura Plena com habilitação específica para formação de professores de ER, entidades religiosas e educacionais confessionais buscavam suprir essa carência promovendo a formação, por meio de cursos, seminários, encontros e outras modalidades. Entre elas destacam-se a Conferência Nacional dos Bispos do Brasil (CNBB); o Conselho Episcopal Latino-Americano (Celam); o Conselho Nacional de Igrejas Cristãs (Conic); o Conselho Evangélico Latino-Americano de Educação Cristã (Celadec); a Associação de Escolas Católicas do Brasil (AEC/Brasil); a Associação Nacional de Escolas Luteranas (ANEL) e Secretarias de Educação estadual e municipal.

Convém lembrar que nas décadas de 1980 e 1990, no Brasil, as práticas de ER variavam entre: Ensino Religioso confessional, de evangelização, pastoral escolar, ecumênico e interconfessional. Para essas modalidades, os conteúdos desenvolvidos para a formação de professores estavam alicerçados na teologia, na Bíblia e na doutrina de cada tradição religiosa.

\section{Conferência Nacional dos Bispos do Brasil}

A CNBB é a primeira instituição religiosa a preocupar-se, em âmbito nacional, com a formação de professores de ER.

A partir de 1974, teve início a formação de professores para o ER, com a realização de Encontros Nacionais para Coordenadores e Professores de Ensino Religioso (ENER) ${ }^{1}$, favorecendo a discussão, definição e organização curricular desse ensino. Assim, de 1974 até 1998, foram realizados 12 Encontros Nacionais.

A preocupação com o ER, respeitando a pluralidade cultural religiosa do povo brasileiro, aparece mais acentuada a partir do $7^{\circ}$ ENER,

\footnotetext{
${ }^{1}$ Esses encontros eram promovidos pelo CNBB e realizados de dois em dois anos. Durante a Assembleia Nacional Constituinte, foram realizados anualmente. Posterior a 1988, o CNBB continuou promovendo esses encontros, novamente de dois em dois anos, até 1998. A partir de 1996-1997, o Fonaper assumiu com competência a parte política e pedagógica do ER. O CNBB passou, então, a dar maior atenção à formação de professores de ER das Escolas Católicas.
} 
promovido pela CNBB e realizado em Brasília, DF, em 1988. A partir dele, os ENERs posteriores, com diferentes enfoques, trataram da pluralidade cultural religiosa do povo brasileiro, da formação de professores, do pedagógico e da busca de identidade do ER (CNBB, 2001).

Durante e a partir do $11^{\circ}$ ENER, de posse dos resultados de ampla pesquisa sobre a situação do ER no Brasil, pela primeira vez os participantes definiram princípios norteadores para as escolas públicas.

O Ensino Religioso, valorizando o pluralismo e a diversidade cultural, presentes na nossa sociedade, tem como finalidade facilitar a compreensão do educando em relação a si próprio; ao outro que o diferencia; ao mundo com e no qual se inter-relaciona e ao Transcendente que se manifesta, plural e diverso, no processo histórico de construção da Humanidade. O ensino religioso deverá garantir e afirmar o direito à diferença na produção de uma civilização solidária e que tenha na liberdade o seu valor inalienável. O Ensino Religioso reconhece que a escola é o lugar privilegiado para o exercício e o aprendizado destes valores e para o confronto sadio deste mesmo pluralismo e desta mesma diversidade (CNBB, 2001).

Após este encontro, realizou-se em Brasília, DF, a primeira sessão do Fonaper ${ }^{2}$, que assume e coordena em âmbito nacional a elaboração dos Parâmetros Curriculares Nacionais para o ER (PCNER), bem como, com o apoio de outras entidades, a política para uma nova redação do Artigo 33 da Lei n. 9.394/96. Com dinamismo, o Fórum desenvolve iniciativas provocadoras, acelerando o processo de formação de professores para ER. A partir de 2000, a CNBB, em parceria com a Associação de Escolas Católicas do Brasil (AEC/Brasil), inicia a promoção de seminários e encontros para a formação desses professores das Escolas Católicas.

Nesses encontros, a formação de professores apoia-se nos conteúdos relacionados ao objeto de estudo, objetivo, conteúdo curricular,

\footnotetext{
${ }^{2}$ O Fonaper foi instalado em 26 de setembro de 1995, em Florianópolis, por ocasião dos 25 anos da primeira experiência de Educação Religiosa Escolar, uma proposta aberta a todo o educando, para as escolas públicas de Santa Catarina, e, ao mesmo tempo, dos 25 anos do Conselho de Igrejas para Educação Religiosa Escolar (CIER). É uma sociedade civil de âmbito nacional, sem vínculo político-partidário, confessional e sindical, sem fins lucrativos, sem prazo determinado de duração, que congrega, conforme este Estatuto, pessoas jurídicas e pessoas físicas identificadas com o Ensino Religioso Escolar e se constitui em um organismo que trata questões pertinentes ao ER, sem discriminação de qualquer natureza. Para mais informações, ver http://www.fonaper.com.br/
} 
metodologia didático-avaliativa, linguagem, história e o espaço cultural. Este ensino passa a ser cada vez mais entendido como um componente curricular integrado às ações pedagógicas e do direito do cidadão. A tônica constante em todos os ENERs ${ }^{3}$ realizados de 1974 a 1998 é a formação de professores e a identidade do ER (CNBB, 2001).

\section{Conselho Episcopal Latino-Americano}

$\mathrm{Na}$ década de 1990, o Conselho Episcopal Latino-Americano (Celam) promoveu vários encontros para, entre outras questões, tratar da formação de professores. Destacam-se os encontros de 1997, no Equador, e o de 1999, na Colômbia.

OCelam (1999) destaca existirem várias iniciativas em universidades católicas da América Latina, para a formação de professores de Educação Religiosa Escolar (ERE), é claro, com configurações diferentes: Ciências Religiosas, Catequese Escolar, Pedagogia da Fé, Ciências da Educação, com especialização em Educação Religiosa. Essas expressões revelavam a compreensão do ER em função da cristandade.

\section{Conselho Nacional de Igrejas Cristãs}

O Conselho Nacional de Igrejas Cristãs (Conic) promoveu encontros de formação de professores, entre as décadas de 1980 e 1990, com a preocupação da identidade do ER, na modalidade confessional ecumênico, entendendo que, para tal, é imprescindível a formação de professores. A prioridade da formação está no conhecimento de conteúdos bíblicos e a preocupação maior é com a evangelização cristã.

A partir da década de 1990, o Conic inclui em suas linhas de ação questões relacionadas ao Ensino Religioso. Em sua estrutura, mantém a Comissão de Ensino Religioso e Educação para o Ecumenismo ${ }^{4}$, responsável

\footnotetext{
${ }^{3}$ Nos arquivos do Setor de Ensino Religioso do CNBB, encontra-se o Relatório de cada um dos Encontros Nacionais de Coordenadores e Professores de Ensino Religioso, entre 1974 e 1998, bem como nas bibliotecas pessoais da profa. Dra. Lurdes Caron, da profa. Dra. Anísia de Paulo Figueiredo (Belo Horizonte, MG) e do prof. Dr. Sérgio Azevedo Junqueira.

${ }^{4}$ Disponível em: <http://www.conic.org.br/?system=news\&eid=193>. Acesso em: 28 ago. 2007.
} 
por acompanhar e elaborar material de apoio ao ER e ao diálogo entre as diferentes denominações religiosas cristãs (CIPRIANI, 2007).

\section{Conselho Evangélico Latino-Americano de Educação Cristã}

O Conselho Evangélico Latino-Americano de Educação Cristã (Celadec) da Região Sul do Brasil promoveu, em julho de 1993, em São Leopoldo, RS, o Simpósio Nacional "Ensino Religioso: uma proposta ecumênica". Em 1998, aconteceu o Congresso Latino-Americano, realizado em Assunção, no Paraguai, com esta temática: "Nuevos caminos pedagógicos frente al tercer milenio". Entre os dez temas para as oficinas, um tratava do Ensino Religioso nas escolas, com a preocupação da formação de professores. O modelo de ER é ecumênico-cristão, portanto, confessional e com a preocupação do ensino bíblico. O professor teria a responsabilidade de ser evangelizador e testemunha cristã.

\section{Associação de Escolas Católicas no Brasil}

A Associação de Escolas Católicas no Brasil (AEC), hoje Associação Nacional de Educação Católica no Brasil (ANEC), em suas atividades, desenvolveu ações para formação de professores; dando atenção a questões do ER.

Em 1984, promoveu o $1^{\circ}$ Seminário Nacional do Ensino Religioso na Escola Católica, realizado em Brasília, de 6 a 9 de janeiro do mesmo ano, com a temática da formação de professores.

Em âmbito nacional, em 2000, foi retomada com ênfase a formação de professores de ER na escola católica, com a realização de Seminário para o Ensino Religioso no Novo Milênio, e em 2002, com a promoção de um novo seminário, também em âmbito nacional, sobre a Formação de Professores de ER nas escolas católicas. Ambos foram realizados em Campinas, SP.

A AEC/ANEC, organizada nacional e regionalmente, promove cursos, seminários e encontros visando à formação de professores para esse ensino em várias regionais. Entre outras experiências, destacam-se os Cursos de Pós-Graduação com Especialização para professores de ER, realizados pela AEC de Pernambuco, em articulação com Universidade Católica de 
Pernambuco (Unicap); os promovidos pela AEC de São Paulo, entre 1994 e 1998, em parceria com a Pontifícia Universidade Católica de São Paulo (PUC-SP); e pelas AECs do Rio Grande do Sul e do Paraná.

\section{Associação Nacional das Escolas Luteranas}

A Associação Nacional das Escolas Luteranas (ANEL), com sede em Porto Alegre, RS, envolve professores da Igreja Evangélica Luterana do Brasil (IELB) e da Igreja Evangélica de Confissão Luterana no Brasil (IECLB). A ANEL desenvolve e articula ações para formação de professores de ER.

O Fórum Nacional Luterano de Ensino Religioso (Fonaluter), realizado em 2003, tratou da formação de professores evangélicos e obreiros para a área da Educação Cristã, e destacou o investimento do Departamento de Catequese na elaboração de materiais didáticos e na capacitação de professores ao ER nas escolas comunitárias e públicas.

A Igreja Evangélica de Confissão Luterana no Brasil (IECLB), preocupada com a formação de professores para o ER, promove, desde 1998, um Curso de Especialização lato sensu em ER, aberto à participação de professores, independente de seu credo religioso.

\section{Secretarias de Educação estaduais e municipais}

As Secretarias de Educação, em cada Estado e nos municípios, de acordo com sua realidade, têm desenvolvido inúmeras iniciativas para a formação de professores nas modalidades de treinamentos, atualizações, aprofundamento, reciclagens e formação continuada. No entanto, no Brasil permanece a carência de políticas públicas para a efetiva formação de professores.

Em síntese: toda a preocupação das entidades religiosas confessionais e educacionais nas décadas de 1980 e 1990 teve grande influência na formação de professores de ER, mesmo que esta formação estivesse mais fundamentada nos valores cristãos, na fé e nos princípios doutrinais de cada denominação religiosa, do que na dimensão pedagógica.

As constantes mudanças sociais, políticas, econômicas, culturais, religiosas, educacionais e os estudos provocados pelos Encontros Nacionais 
promovidos pelo $\mathrm{CNBB}$ e por outras entidades desafiam entidades envolvidas com a formação de professores de ER, mas, acima de tudo, os próprios professores na busca de formação.

\section{Fórum Nacional de Reflexão Permanente do Ensino Religioso: formação de professores}

A partirdos Encontros Nacionais de Ensino Religioso promovidos pelo CNBB e dos Seminários do Conic, Celadec, Secretarias Estaduais e Municipais de Educação e outros, os professores passaram a encontrar-se, conhecer-se, partilhar experiências e organizar-se mais.

Assim, em 26 de setembro de 1995, em Florianópolis, SC, durante a realização da $29^{a}$ Assembleia Ordinária do Conselho de Igrejas para a Educação Religiosa (CIER) de Santa Catarina, na comemoração dos 25 anos de sua existência, é instalado o Fórum Nacional de Reflexão Permanente do Ensino Religioso (Fonaper), que exerce importante função política na sociedade e na educação brasileiras, sobretudo na orientação pedagógica, no que se refere ao Ensino Religioso no País.

O evento contou com a presença de 42 entidades educacionais e religiosas, com professores representando 15 unidades da Federação. Na mesma data, foi elaborada a "Carta de Princípios" que rege o Fórum. Desde sua instalação, o Fonaper busca acompanhar, organizar e subsidiar o esforço de professores, associações e pesquisadores no campo do ER.

Em um primeiro momento, ocupou-se da promulgação da LDB e da Lei n. 9.475. Simultaneamente, foram elaborados e divulgados os Parâmetros Curriculares Nacionais do Ensino Religioso (PCNER), que subsidiam debates e encaminhamentos de propostas a este ensino, assumido pelo MEC para divulgação e publicado pela Editora Ave Maria.

O modelo de Ensino Religioso proposto pelo Fonaper e definido pela Lei n. 9.475 tem como ponto de partida o pedagógico e não o religioso.

Diante da nova concepção de ER definida na Lei n. 9.475/97 e nos PCNER, o Fonaper assume o processo de formação de docentes para o ER; desenvolve e promove uma série de estratégias políticas que, aos poucos, foram abrindo caminhos para a formação em serviço; elabora, sistematiza e divulga pelo Brasil as Diretrizes de Capacitação Docente - Licenciatura - lato 
sensu-Extensão para o ER (FONAPER, 1998) e as encaminha ao Ministério da Educação/Conselho Nacional de Educação ${ }^{5}$. Esse documento serve de "marco referencial" para a formação continuada dos profissionais do ER e para as IES, na organização e promoção de cursos para esta finalidade.

A fim de ajudar os professores na implementação do atual modelo para o ER, o Fórum Nacional Permanente de Ensino Religioso elabora os Parâmetros Curriculares Nacionais do Ensino Religioso; os Cadernos Temáticos - Ensino Religioso: referencial curricular para a proposta pedagógica da escola; Ensino Religioso: culturas e tradições religiosas (1 e 2) e os Cadernos para o Curso a Distância - Ensino Religioso: capacitação para um novo milênio (12), incluindo estudos sobre ER e o Fenômeno Religioso nas Tradições Religiosas de matriz indígena, ocidental, africana e oriental.

Entre 2000 e 2005, o Fonaper desenvolveu um curso de extensão a distância com duração de 120 horas, intitulado Ensino Religioso: capacitação para um novo milênio. O primeiro curso, em 2001, foi veiculado pela Rede Vida de Televisão, e o segundo, em 2002, pela TVE do Paraná. Participaram mais de 4.500 professores (VIESSER, 2002). A partir de 2005, o curso continuou na modalidade de contrato de prestação de serviços, organizado em 12 módulos (12 fitas de vídeo e 12 cadernos).

O Fonaper continua a preocupar-se prioritariamente com a formação de docentes ao Ensino Religioso (JUNQUEIRA; WAGNER, 2004; CARON, 2005). Para isso, organiza e viabiliza desde 1996 seminários de capacitação docente, sessões de estudos, assembléias, congressos, além de manter a web, atualizada. Até 2009, realizou 17 sessões ordinárias, uma extraordinária, nove seminários para capacitação docente e cinco Congressos Nacionais de Ensino Religioso (Conere).

Apesar de todo o esforço do Fonaper, no Brasil registra-se a carência de políticas públicas que incluam a formação de professores para o ER. Há um longo caminho a ser percorrido, pois o ER ainda não é uma disciplina consolidada no currículo escolar. Está definido em legislação e continua alvo de diferentes interpretações do próprio aspecto legal e das concepções que o envolvem.

\footnotetext{
${ }^{5}$ Em 1988, o Fonaper encaminhou ao MEC/CNE, pela primeira vez, as diretrizes elaboradas para a formação de professores de Ensino Religioso. Foram entregues pessoalmente ao presidente do CNE, mas não houve resposta. Em 2004, com o apoio do conselheiro Francisco Cordão, o Projeto com nova redação, trabalhada pela Comissão de Formação do Fonaper, foi também encaminhado ao CNE. O Fonaper continua sua luta em prol das diretrizes de formação de professores.
} 
Em 2010, o Fonaper é debutante. Completa 15 anos de esforço e trabalho em reflexões para a compreensão do ER, da formação de professores e do fazer pedagógico no cotidiano da sala de aula.

\section{Formação de professores de ensino religioso no Estado de Santa Catarina}

A LDB, quando de sua promulgação, em 20 de dezembro de 1996, fixou o início da década da educação, quanto à formação para a função de docentes. ${ }^{6}$ Pelo dispositivo legal desta lei, ao fim da década de 1990, os professores da educação básica deveriam ter no mínimo o curso de Graduação.

O Estado de Santa Catarina, visando a responder às exigências do Plano Decenal de Educação para todos (1993-2003), da LDB e das Diretrizes Curriculares Nacionais da Educação Básica (DCNEB), entre 1995 e 1996 organizou o plano de políticas de formação, inicialmente pelo Programa Magister, ${ }^{7}$ que é uma ação governamental voltada à formação continuada de professores não habilitados, nas diferentes áreas. Entre os vários cursos, incluiu no Programa Magister ${ }^{8}$ CCR/LP/ER.

A partir de 1996, acentuam-se no Estado as discussões em vista de atender a demanda de um profissional devidamente habilitado para ensinaraprender-ensinar pedagogicamente a diversidade do fenômeno religioso, isto é, ação-reflexão-ação. Com esta finalidade, foram criados, Cursos de Ciências da Religião - Licenciatura Plena em Ensino Religioso (CCR/ $\mathrm{LP} / \mathrm{ER}$ ), que buscam formar um profissional na perspectiva da leitura do fenômeno religioso no contexto escolar e social.

\footnotetext{
${ }^{6}$ CARON, 2005, p. 99-117. Pode-se aprofundar leituras sobre diferentes aspectos da LDB em SAVIANI, 1999; CARNEIRO, 1998, e outros autores.

${ }^{7}$ A Secretaria de Estado da Educação e Desporto (SED) de Santa Catarina implantou o Programa Magister em articulação com 11 Universidades Regionais, a Universidade do Estado e a Universidade Federal de Santa Catarina. Foram desenvolvidos cursos de Licenciatura Plena para a habilitação de professores em diferentes áreas: Ciências Naturais e Matemática, Pedagogia - Séries iniciais, Pedagogia - Educação Especial, Ciências Física, Ciências - Biologia, Letras - Português e Inglês, Ciências Sociais - Geografia e História, Ciências Química, Ciências da Religião, Letras - Português e Espanhol, Letras - Português e Italiano, Letras - Português e Alemão, Educação Artística. Ao todo, nas respectivas áreas, entre os concretizados e os em ação, são 104 cursos. ${ }^{8}$ ESTADO DE SANTA CATARINA, 1998, p. 5. O Programa Magister, criado pela Diretoria de Ensino Superior - DESU/SED, é uma ação do Governo do Estado de Santa Catarina que busca a melhoria da Educação, pela formação de professores das áreas mais deficitárias do magistério catarinense. Trata-se de formação continuada em serviço. Este Programa busca ações emergenciais para suprir a rede estadual e municipal de ensino com recursos humanos qualificados, objetivando a melhoria da qualidade de ensino.
} 
As discussões e projetos para implantação de curso de Licenciatura Plena (LP) para formação de professores em ER, em Santa Catarina, iniciaram em 1972. O Projeto para LP na disciplina para formação de docentes de ER, em andamento desde 1972, foi assumido pela Universidade Regional de Blumenau. A Portaria 37/96 emitida por seu reitor, datada de 22 de março de 1996, designou uma Comissão Especial de Estudos para montagem do projeto do Curso de Ciências da Religião (OLIVEIRA, 2004).

No decorrer de 1996, duas outras IES do Estado (Universidade da Região de Joinville e Universidade do Sul de Santa Catarina), empreenderam processo similar para a criação de CCR/LP/ER (CIER, 1996).

\section{Licenciatura Plena em Ensino Religioso: novas perspectivas}

No segundo semestre de 1996, iniciou-se o CCR/LP/ER na Universidade Regional de Blumenau (FURB), na Universidade Regional de Joinville (Univille) ena Universidade do Sulde Santa Catarina (Unisul) - Tubarão, com extensão para o câmpus da Grande Florianópolis, no município de Palhoça; para a Unoesc, câmpus de Xanxerê; e UnC, câmpus de Curitibanos. A modalidade do curso seguiu as mesmas exigências dos demais cursos.

O CCR/LP/ER foi reconhecido pelo Conselho Estadual de Educação (CEE/SC). A partir de 2001, no concurso de provas e títulos para ingresso e efetivação no Quadro do Magistério Público Estadual de Santa Catarina, passaram a ser incluídas vagas para professores licenciados com habilitação em ER. Em 2005, novo concurso foi realizado. Outros municípios fizeram o mesmo, nos concursos públicos para o Quadro do Magistério do Município.

Entre a Unisul, Univille e FURB, de 1996 a 2006, foram oito turmas de acadêmicos formados com a Licenciatura Plena em ER pelo Programa Magister. A Univille e a FURB vêm oferecendo o Curso de Licenciatura Plena com habilitação em ER de forma regular.

A partir de 2008, o CCR/LP/ER passou a ser ofertado pela Universidade Regional Comunitária de Chapecó (Unochapecó) e pela Universidade de São José (USJ), no município de São José. Em 2009, com o Plano Nacional de Formação de Professores da Educação Básica, 
desenvolvido pelo MEC, na Plataforma Paulo Freire' , outras IES do Estado passaram a desenvolver o CCR/LP/ER.

\section{Professores com licenciatura plena em Ensino Religioso no Programa Magister}

O CCR/LP/ER, por meio do Programa Magister, é desenvolvido pela FURB, Univille e Unisul (esta com extensão para quatro IES). A Tabela 1 a seguir demonstra, em síntese, o número de acadêmicos com Licenciatura Plena em Ensino Religioso pelo Programa Magister e o movimento na continuidade da formação de professores.

Tabela 1 - Registro do número de acadêmicos formados no Curso de Ciências da Religião-Licenciatura Plena-habilitação em Ensino Religioso, pelo Programa Magister nas IES: FURB, Univille e Unisul (câmpus de Tubarão, câmpus da Pedra Branca, na Grande Florianópolis - Ponta de Imarui, Universidade do Contestado - Curitibano e Universidade do Oeste de Santa Catarina - câmpus de Xanxerê)

(continua)

\begin{tabular}{llll}
\hline $\begin{array}{l}\text { Entidade } \\
\text { Educacional }\end{array}$ & Período & Programa / Curso & $\begin{array}{l}\text { Número de } \\
\text { Acadêmicos } \\
\text { Formados }\end{array}$ \\
\hline FURB & $1996-2004$ & $\begin{array}{l}\text { Programa Magister } \\
\text { CCR/LP/ER } \\
\text { Curso de Pós-Graduação }\end{array}$ & $\mathbf{8 3 \text { acadêmicos }}$ \\
& 2000 & $\begin{array}{l}\text { Lato Sensu - Especialização } \\
\text { Fundamentos e Metodologia } \\
\text { ER }\end{array}$ & $\begin{array}{l}34 \text { acadêmicos } 1^{\text {a }} \\
\text { Turma }\end{array}$ \\
& 2004 & Idem & 39 acadêmicos 2 $2^{\text {Turma }}$ \\
& 2006 & Idem & 24 acadêmicos 3 $3^{\text {a Turma }}$ \\
\hline
\end{tabular}

${ }^{9}$ Essa plataforma favorece o acesso dos professores da educação básica pública às vagas oferecidas pelas IES (Ver http:// freire.mec.gov.br). A Secretaria de Estado da Educação, sob a coordenação da CAPES, elaborou, com representantes da Undime/SC, UFSC, UDESC, IF-SC (antigo CEFET), ACAFE e do SINTE, um planejamento estratégico para atender à demanda de Formação Inicial dos professores em exercício nas escolas públicas (CECCHETTI, 2009). 
Tabela 1 - Registro do número de acadêmicos formados no Curso de Ciências da Religião-Licenciatura Plena-habilitação em Ensino Religioso, pelo Programa Magister nas IES: FURB, Univille e Unisul (câmpus de Tubarão, câmpus da Pedra Branca, na Grande Florianópolis - Ponta de Imarui, Universidade do Contestado - Curitibano e Universidade do Oeste de Santa Catarina - câmpus de Xanxerê)

(conclusão)

\begin{tabular}{|c|c|c|c|}
\hline \multirow[t]{3}{*}{ Univille } & $1996-2004$ & $\begin{array}{l}\text { Programa Magister } \\
\text { CCR /LP/ER }\end{array}$ & 75 acadêmicos \\
\hline & 2002 & $\begin{array}{l}\text { Início da Especialização } \\
\text { Latu Sensu - Curso de } \\
\text { Fundamentos e Metodologia } \\
\text { do Ensino Superior } 420 \\
\text { horas/aula }\end{array}$ & 24 acadêmicos \\
\hline & 2009 & Novo curso Especialização & Em projeto \\
\hline \multirow[t]{5}{*}{ Unisul } & $1996-1999$ & Programa Magister & $\begin{array}{l}46 \text { acadêmicos } \\
\text { (câmpus Tubarão) }\end{array}$ \\
\hline & & & $\begin{array}{l}37 \text { acadêmicos (câmpus } \\
\text { Pedra Branca - Ponta } \\
\text { Imarui - Palhoça) }\end{array}$ \\
\hline & & & $\begin{array}{l}41 \text { acadêmicos } \\
\text { (Universidade } \\
\text { do Contestado - } \\
\text { Curitibanos) }\end{array}$ \\
\hline & & & $\begin{array}{l}36 \text { acadêmicos } \\
\text { (Universidade do } \\
\text { Oeste Xanxerê) }\end{array}$ \\
\hline & & & $\begin{array}{l}\text { Total das quatro } \\
\text { turmas: } 160\end{array}$ \\
\hline
\end{tabular}

Fonte: Relatórios das IES (FURB, 1996a, b; 2003; 2005a, b; 2006a, b; UNISUL, 1996; UNIVILLE, 2004a, b, c), informações de dados por e-mails (HESS, 2006; CECCHETTI, 2009) e relatórios da SEE do Estado de Santa Catarina (1996, 1998).

Em 2004, o contingente de docentes com a Licenciatura Plena, habilitados em ER, por meio do Programa Magister, entre as três Instituições de Ensino Superior (FURB, Unisul e Univille), é de $318^{10}$ professores, o

${ }^{10}$ Alunos formados no Curso de Ciências da Religião - Licenciatura Plena pelo Programa Magister: FURB (83 alunos), Univille (75 alunos) e Unisul (160 alunos), num total de 318 alunos. 
que corresponde a 35\% da professores habilitados em ER necessários para o ensino fundamental no Estado de Santa Catarina, conforme o Relatório do CONER-SC de 2004.

O Relatório do CONER, de 2004, revela a necessidade de, pelo menos, mais 65\% de professores habilitados em ER para atender à rede pública estadual. Significa que, mesmo com a oferta regular do CCR pela FURB e Univille, a carência de professores habilitados continuará existindo. Os dados da pesquisa de 2007 revelaram a necessidade de o CCR/LP/ER ser estendido para outras IES do Estado de Santa Catarina. Para tanto, tornaram-se necessárias políticas públicas de continuidade na formação de professores para atender à demanda.

Com o curso de Ciências da Religião, o leque de oportunidades para professores começa a mostrar novos horizontes. Os resultados que emergem começam fazer a diferença. O quadro do magistério público estadual para melhoria do ensino-aprendizagem, na realização pessoal e profissional dos docentes, mostra que é possível atender à legislação sem fazer exclusão de profissionais da educação, possibilitando a todos o acesso à formação específica.

\section{Formação de professores de Ensino Religioso em curso regular}

Em 2009, em Santa Catarina, entre os matriculados no Programa Magister e nos Cursos Regulares da FURB e Univille, são formados 350 professores pelo CCR/LP/ER (Tabela 2).

Tabela 2 - Registro do CCR/LP/ER regularnas políticas internas de IES e respectivo número de acadêmicos: FURB (Blumenau), Univille (Joinville), Unochapecó (Chapecó) e USJ (São José)

(continua)

\begin{tabular}{llll}
\hline $\begin{array}{l}\text { Entidade } \\
\text { Educacional }\end{array}$ & Período & Programa / Curso & $\begin{array}{l}\text { Número de } \\
\text { Acadêmicos } \\
\text { Formados }\end{array}$ \\
\hline & 2004 & CCR/LP/ER de forma regular & 28 acadêmicos \\
FURB & 2007 & CCR/LP/ER de forma regular & 18 acadêmicos \\
& 2009 & $\begin{array}{l}\text { Finalizando o Curso de } \\
\text { Especialização }\end{array}$ & - \\
\hline
\end{tabular}


Tabela 2 - Registro do CCR/LP/ER regularnas políticas internas de IES e respectivo número de acadêmicos: FURB (Blumenau), Univille (Joinville), Unochapecó (Chapecó) e USJ (São José)

(conclusão)

\begin{tabular}{|c|c|c|c|}
\hline \multirow{3}{*}{ Univille } & 2004 & $\begin{array}{l}\text { CCR/LP/ER de forma regular, } \\
\text { em parceria com o Instituto } \\
\text { EDUCA }\end{array}$ & 44 acadêmicos \\
\hline & 2009 & $\begin{array}{l}\mathrm{CCR} / \mathrm{LP} / \mathrm{ER} \text { regular }-\mathrm{em} \\
\text { projeto }\end{array}$ & - \\
\hline & 2009 & $\begin{array}{l}\text { Curso de Especialização em ER - } \\
\text { em projeto }\end{array}$ & - \\
\hline \multirow{2}{*}{ Unochapecó } & 2009 & Curso de CR/LP/ER (1ª turma) & 30 acadêmicos \\
\hline & 2008 & Curso de CRLP/ER (2 ${ }^{\text {a }}$ turma) & 20 acadêmicos \\
\hline \multirow[t]{2}{*}{ USJ } & 2008 & Curso CR/LP/ER (1 turma) & $\begin{array}{l}\text { Total das duas } \\
\text { turmas: } 63 \\
\text { acadêmicos }\end{array}$ \\
\hline & 2009 & Curso CR/LP/ER (1 turma) & - \\
\hline \multicolumn{3}{|c|}{ Total de acadêmicos em CCR/LP/ER de forma regular das IES } & 203 acadêmicos \\
\hline
\end{tabular}

Fonte: FURB, 2004, 2007, 2009; UNIVILLE, 2004a, b, c; 2009a, b; UNOCHAPECÓ, 2008, 2009; USJ, 2008, 2009.

\section{Plano Nacional de Formação de Professores da Educação Básica}

O Estado de Santa Catarina busca possibilitar a todos os professores a formação específica, com a Licenciatura Plena. Por meio do Plano Nacional de Formação de Professores da Educação Básica, desenvolvido pelo MEC em 2009-2010, o Estado está a oferecer o Curso de Ciências da Religião - Licenciatura Plena em Ensino Religioso para mais professores em diferentes regiões e IES.

Esta expansão do CCR/LP/ER é um fato inédito e possibilita que outros professores de ER tenham acesso à formação específica, com Licenciatura Plena. 


\section{Considerações finais}

O Ensino Religioso, na forma em que está definido pela Lei $\mathrm{n}$. 9.475/97, neste ano de 2009 completa 12 anos de vigência no Brasil. A conquista desta Lei e, a partir dela, os cursos, seminários e outros encontros realizados pelas Instituições de Ensino Superior, por Secretarias Estaduais e Municipais de Educação e por outras entidades, em vista da formação de professores, devem-se, sem dúvida ao esforço e participação de muitas mãos, de muitas pessoas envolvidas e de muitos professores de ER.

Em suas comemorações, o Ano Brasileiro de Ensino Religioso não poderá esquecer dos 15 anos do Fonaper, dos 12 anos da Lei n. 9.475/97 e os 10 anos do Grupo de Pesquisa em Educação e Religião da PUCPR. Todos os que estão envolvidos e compromissados e que acreditam ser "possível um mundo melhor" e que, por meio da educação, pode-se criar a cultura da solidariedade e da paz estão de parabéns e, ao mesmo tempo, desafiados a continuar crescendo, gerando o diálogo, a reverência à diversidade das diferentes culturas, do diferente fazer pedagógico de quem aprende-ensina-aprende e reelabora.

É significativo e importante que o Estado de Santa Catarina tenha optado pelo titulo de Ciências da Religião (CR), mesmo que ainda seja algo novo e não esteja bem formatado na grade curricular. É um curso que, olhando para o futuro, promete mercado de trabalho. O Curso de CR possibilita alargar horizontes para além de aulas de ER, com produções científicas, assessorias aos mais diferentes campos da sociedade que buscam atender à formação do ser humano na sua globalidade (FELLER, 2006).

A política de capacitação docente, em níveldegraduação,implantada em Santa Catarina, pelo Programa Magister, favorece a melhoria nas competências e habilidades de professores e pode servir de incentivo a outros Estados.

O caminho escolhido pelo Estado está possibilitando todas as etapas de formação e dando passos significativos para inclusão no quadro do magistério de professores de ER, com igual tratamento aos demais profissionais da educação. Isso é um fato histórico para o ER no Brasil, pois se trata de um dos primeiros Estados da Federação a oferecer Licenciatura Plena em Ensino Religioso, para profissionais da Educação.

O ER e a formação dos professores significam a possibilidade de uma nova forma de se educar na diversidade cultural religiosa da humanidade, assim como auxiliar na promoção da dignidade, respeito e liberdade individual. 


\section{Referências}

AEC-SP. Relatórios dos CEER. AEC\&PUC-SP. Disponível em: < http://www. cee.sc.gov.br>. Acesso em: 15 out. 2009.

BRASIL. Lei n. 9.394, de 20 de dezembro de 1996. Estabelece as diretrizes e bases da educação nacional. Diário Oficial [da] República Federativa do Brasil, Poder Legislativo, Brasilia, DF, 23 dez. 1996. p. 27833. Disponível em: < http:/ / www6.senado. gov.br/legislacao/ListaTextoIntegral.action?id=75723>. Acesso em: 23 jul. 2009.

. Presidência da República. Lei n. 9.475/97, de 22 jul. 1997. Alteração, normas, correlação, facultatividade, disciplina escolar, religião, estabelecimento de ensino, ensino fundamental, território nacional, competência, sistema de ensino, fixação, conteúdo, disciplina escolar, religião. Diário Oficial [da] República Federativa do Brasil, Brasília, Congresso Nacional, 23 jul. 1997. coluna 2, p. 15824. Disponível em: < http://www6.senado.gov.br/legislacao/ListaNormas. action?tipo_norma=LEI\&numer=009475\&data=1997\&SUBMIT1 =Pesquisar $>$. Acesso em: 21 jan. 2010.

CARON, L. (Org.). O Ensino Religioso na nova LDB: histórico, exigências, documentário. Petrópolis: Vozes, 1997.

. Políticas públicas para a formação de professores para a Educação Básica. In: JUNQUEIRA, S. R. A. et al. (Org.). Ensino Religioso: memória e perspectivas. Curitiba: Champagnat, 2005. p. 99-117.

CECCHETTI, E. (elcio.educ@terra.com.br). Versão eletrônica de manuais [mensagem pessoal]. Formação de professores de ER por meio do Plano Nacional de Formação de professores para educação básica. Mensagem recebida porlurcaron@gmail.com em: 06/08/09 e 27/11/09.

CIPRIANI, Gabriel. (conic.gabriele@terra.com.br). Versão eletrônica [mensagem pessoal]. Informações sobre o Ensino Religioso no CONIC. Mensagem recebida porlurcaron@terra.com.brem: 25/04/2007.

CONFERENNCIA NACIONAL DOS BISPOS DO BRASIL - CNBB. Relatórios dos Encontros Nacionais do Ensino Religioso 1974-1998. Brasília: CNBB Setor de Ensino Religioso, 2001.

CONSELHO DE ENSINO RELIGIOSO DE SANTA CATARINA - CONERSC. Relatório de atividades. Florianópolis: CONER, 2004. (polígrafo) 
CONSELHO DE IGREJAS PARA A EDUCAÇÃO RELIGIOSA - CIER-SC. Ata da Assembleia realizada em 17 set. 1996. Florianópolis: CIER, 1996. p. 1-3. (Mimeo.).

ESTADO DE SANTA CATARINA. Secretaria de Estado da Educação e do Desporto / Secretaria de Estado da Administração. Parecer n. 141/96, aprovado em 23/04/96. Florianópolis: GOV/SEED/SEA, 1996. (Mimeo.).

. Instituições de Ensino Superior. Programa Magister: informações gerais. Florianópolis: SEE/IES, 1998. (Mimeo.).

. Decreto n. 3.882, de 28 de dezembro de 2005. Regulamenta o Ensino Religioso nas escolas de Ensino Fundamental da rede pública estadual. Florianópolis: Santa Catarina, 2005. Disponível em: <http://www.sed.sc.gov. $\mathrm{br} /$ secretaria/documentos/cat_view/58-legislacao/185-ensino/76-legislacaoestadual/81-decretos >. Acesso em: 25 out. 2009.

FELLER, V. G. Entrevista sobre o CCR/LP/ER/SC. Florianópolis: ITESC, 2006.

FREIRE, P. Pedagogia da autonomia: saberes necessários à prática educativa. 22. ed. Rio de Janeiro: Paz e Terra, 2002.

FÓRUM NACIONAL PERMANENTE DO ENSINO RELIGIOSO FONAPER. Capacitação Docente: Licenciatura - Lato Sensu - Extensão para o Ensino Religioso. Brasília: Divisão Gráfica - UCB, 1998. Disponível em: <http:/ / www.fonaper.com.br>. Acesso em: 25 out. 2009.

HESS, C. (cilicili@uol.com.br). Versão eletrônica de manuais [mensagem pessoal]. Informações sobre o Curso de Ciência da Religião Licenciatura Plena em Ensino Religioso (CCRLPER): acadêmicos da Univille - Joinville. Mensagem recebida por lurcaron@terra.com.br em: 7 set. 2006.

JUNQUEIRA, S. R. A.; WAGNER, R. (Org.). Ensino Religioso no Brasil. Curitiba: Champagnat, 2004.

OLIVEIRA, L. B. de. Formação de docentes para o ensino religioso: perspectivas e impulsos a partir da ética social de Martinho Lutero. 2003. 230 f. Tese (Doutorado em Teologia) - Escola Superior de Teologia de São Leopoldo, São Leopoldo, 2003.

2004. (Mimeo.).

. Diretrizes para Formação de professores de ER. Blumenau: FURB, 
UNIVERSIDADE COMUNITÁRIA REGIONAL DE CHAPECÓ UNOCHAPECÓ. Relatórios do CCR/LP/ER da Unochapecó. Chapecó: [s.n.], 2008. (Informações pessoais obtidas com a professora Teresa Machado Dill, coordenadora do Curso de Ciências da Religião - Habilitação em Ensino Religioso, em fev./maio de 2009).

Relatórios do CCR/LP/ER da Unochapecó. Chapecó: [s.n.], 2009. (Informações pessoais obtidas com a professora Teresa Machado Dill, coordenadora do Curso de Ciências da Religião - Habilitação em Ensino Religioso, em fev./maio de 2009).

UNIVERSIDADE DA REGIÃO DE JOINVILLE - UNIVILLE. Parecer $\mathbf{n}$. 280/04, de 15 julho de 2004. Reestruturação do Curso de Licenciatura Plena em Ciências da Religião. Joinville: Univille, 2004a.

. Pró-Reitoria de Ensino. Coordenação do Curso de Ciências da Religião. Parecer da Comissão, 17 de junho de 2004. Joinville: Univille, 2004b.

- Pró-Reitoria de Ensino. Coordenação do Curso de Ciências da Religião. Portaria n. 030/2004 - PROEN. Joinville: Univille, 2004c.

Relatório do CCR/LP/ER regular. Joinville: [s.n.], 2009a.

. Relatório / Especialização em Ensino Religioso. Joinville: [s.n.], 2009b.

UNIVERSIDADE DE SÃO JOSÉ - USJ. Relatório do CCR/LP/ER da USJ. São José, SC: [s.n.], 2008. (Informações pessoais obtidas por Lurdes Caron com a professora coordenadora do Curso de Ciências da Religião - Habilitação em Ensino Religioso, em abr./maio de 2009).

. Relatório do CCR/LP/ER da USJ. São José, SC: [s.n.], 2009. (Informações pessoais obtidas por Lurdes Caron com a professora coordenadora do Curso de Ciências da Religião - Habilitação em Ensino Religioso, em abr./maio de 2009).

UNIVERSIDADE DO SUL DE SANTA CATARINA - UNISUL. Projeto de criação do Curso de Ciências da Religião - habilitação: licenciatura do $1^{\circ} \mathrm{e}$ $2^{\circ}$ graus em Educação Religiosa Escolar. Tubarão: Unisul, 1996.

UNIVERSIDADE REGIONAL DE BLUMENAU - FURB. Portaria n. 37/96 de 22 de março de 1996. Blumenau: FURB, 1996a.

. Projeto de autorização do Curso de Licenciatura Plena em Ciências da Religião: habilitação em Ensino Religioso. Blumenau: FURB, 1996b. 
. Política das Licenciaturas. Blumenau: FURB, 2003.

. Relatório do CCR/LP/ER regular. Blumenau: [s.n.], 2004.

. Processo de Renovação do Reconhecimento do Curso em Ciências da Religião: Licenciatura Plena em Ensino Religioso. Blumenau: FURB, 2005a.

. Memorando n. 28/2005, 26 de setembro de 2005. Blumenau: FURB, 26 de setembro de 2005 b.

. Quadro estatístico de ingressos no Curso de Ciências da Religião. Blumenau: FURB/DRA, 2006a.

. Quadro estatístico: soma de alunos do Curso de Ciências da Religião por ano e semestre. Blumenau: FURB/DRA, 2006b.

. Relatório do CCR/LP/ER regular. Blumenau: [s.n.], 2007.

. Relatório / Especialização em Ensino Religioso. Blumenau: [s.n.], 2009.

VIESSER, L. C. Relatório do curso a distância em Ensino Religioso. In: ASSEMBLEIA DO FÓRUM NACIONAL PERMANENTE DO ENSINO RELIGIOSO, 1., 2002, São Paulo. Apresentação oral... São Paulo: [s.n.], 2002.

Recebido: 30/11/2009

Received: 11/30/2009

Aprovado: 10/03/2010 Approved: 03/10/2010 